\title{
A Lógica da Suposição e a Compreensão do Faz-de- Conta por Parte das Crianças
}

\author{
Maria da Graça Bompastor Borges Dias ${ }^{1,2}$ \\ Antonio Roazzi \\ Universidade Federal de Pernambuco \\ David O'Brien \\ Baruch College and Graduate Center of the City University of New York, USA \\ Martin D. S. Braine \\ New York University (in memoriam)
}

\begin{abstract}
Resumo
Os estudos sobre a teoria da lógica mental para o raciocínio condicional não revelam se crianças fazem julgamentos que são consistentes com o procedimento semântico dessa teoria para se. Foram realizados dois experimentos com crianças de seis a 11 anos e adultos universitários brasileiros e norte-americanos. Os mesmos foram apresentados a problemas silogísticos de diferentes formas. Os resultados mostram que crianças em idade escolar, como também os universitários, fazem julgamentos que são consistentes com os procedimentos semânticos da lógica mental para se. Assim, há razões para se pensar que existe uma lógica para condicionais que se centraliza na suposição e que está disponível logo cedo na linguagem e no raciocínio das crianças.

Palavras-chave: Teoria da lógica mental; condicionais; faz-de-conta.
\end{abstract}

The Logic of Supposition and Children's Understanding of Make-Believe Play

Abstract

The mental-logic theory's studies for conditional reasoning did not adress whether children make judgments that are consistent with the mental-logic procedural semantics for if. There were two experiments with six to 11 year old children and college students from Brazil and United States of America who were presented to syllogistic problems in different forms. The results show that school children, as well as adults, make judgments that were consistent with the mental-logic procedural semantics for if. Thus, there are reasons to think that there is a logic for condicionals that centers on supposition that is available early in the language and reasoning of children.

Keywords: Mental logic theory; conditionals; make-believe.

Investigadores do raciocínio condicional chegaram a um conjunto amplamente diverso de conclusões relativas à amplitude na qual crianças ou adultos têm compreensão apropriada de condicionais, isto é, proposições na forma $S_{e} P$ então $Q$. Em uma extremidade do espectro está um pesquisador do raciocínio em adultos, argumentando que "o desempenho indica apenas uma compreensão superficial da sentença $S_{e} P$ então $Q$ e pequena evi-

Endereço para correspondência: Av. Beira Mar, 520, apt ${ }^{\circ}$. 81, Piedade Jaboatão, PE, 54400-010, E- mail: Mdias@npd.ufpe.br. Fones: (81) 3361 2319, 3271-8272, Fax (81) 3271-1843

Parte deste trabalho foi publicado em Braine, M.D.S. \& O’Brien, D.P. (1998). Mental Logic, Mahwah, N.J.: Laurence Erlbaum.

Pesquisa Financiada pelo CNPq dência de qualquer compreensão mais profunda." (Evans, 1982, p. 231) No outro extremo, estão aqueles, como nós, que concluem que crianças pequenas apresentam evidência de apreciação considerável da lógica de condicionais (Dias \& Harris, 1988, 1990; Ennis, 1971, 1975). Entre esses dois extremos estão aqueles que defendem um cenário desenvolvimental no qual adultos e adolescentes têm uma apreciação adequada de condicionais (sujeito a alguns limites de desempenho), embora as crianças tenham uma compreensão incompleta ou insuficiente (Knifong, 1974; Kuhn, 1977; Markovits, 1984, 1985 Matalon, 1962; Moshman, 1979; Overton, 1990; Paris, 1973; Staudenmayer \& Bourne, 1977; Taplin, Staudenmayer \& Taddonio, 1974; Ward \& Overton, 1990). Segundo esses autores, o modo como os adultos 
compreendem condicionais é qualitativamente diferente do modo como as crianças os compreendem.

Propomos que estas disparidades originam-se de diferenças teóricas sobre o que constitui uma compreensão apropriada de condicionais e, conseqüentemente, de diferenças nos tipos de tarefas de raciocínio que têm sido apresentadas. Aqueles pesquisadores que concluíram que as pessoas (crianças ou adultos) não têm uma compreensão apropriada de condicionais, têm usado a Tabela da Verdade para o condicional material (apresentada na Tabela 1) como um modelo normativo, e têm comparado o desempenho dos participantes com o que seria predito a partir desta tabela. Observando-se a Tabela 1 verifica-se que para o material condicional uma proposição com o se é verdadeira, a menos que seu antecedente seja verdadeiro e sua conclusão falsa. Em particular, esta interpretação torna um condicional verdadeiro sempre que seu antecedente for falso, algo que os pesquisadores descobriram que as pessoas não aceitam (ver Evans, Newstead \& Byrne, 1993, para uma revisão de conjuntos de dados com adultos para as principais tarefas baseadas no material condicional).

Tabela 1. Tabela da Verdade da Lógica Padrão para Material Condicional

\begin{tabular}{ccc}
$\begin{array}{c}\text { Status verdadeiro } \\
\text { dos componentes } \\
\text { da proposição }\end{array}$ & $\begin{array}{c}\text { Status verdadeiro dos com- } \\
\text { ponentes da proposição }\end{array}$ \\
\hline P & Q & P $>$ Q \\
V & V & V \\
F & V & V \\
V & F & F \\
F & F & V
\end{tabular}

Legenda: $\quad \mathrm{V}=$ verdadeiro $\quad \mathrm{F}=$ falso

O fato das pessoas não responderam de acordo com as formas previstas pela Tabela da Verdade para o material condicional tem sido interpretado por alguns pesquisadores como evidência da ausência de competência para o raciocínio condicional. Chegamos a uma conclusão diferente: tais respostas mostram que a Tabela da Verdade não capta o que as pessoas entendem sobre condicionais. De fato, observar os condicionais atravé das lentes da Tabela da Verdade obscurece o papel dos condicionais no raciocínio quotidiano: se indica suposição e a pessoa ao raciocinar geralmente supõe alguma coisa para descobrir como seria se esta suposição fosse verdadeira. Portanto, o raciocínio condicional diz respei- to a situações hipotéticas e de faz-de-conta e ao que se segue a partir delas. Enquanto que o material condicional não capta nada desta natureza suposicional do raciocínio condicional, a visão de condicionais a partir da perspectiva de uma lógica mental de esquemas de inferência, o faz.

A Teoria da Lógica Mental sobre se inclui alguns esquemas de inferência, um programa de raciocínio que aplica os esquemas na linha de raciocínio e alguns princípios pragmáticos motivados independentemente. Os esquemas de inferência e as rotinas de raciocínio direto são a lógica mental básica e, aquelas inferências que podem ser realizadas nesta parte básica, devem ser feitas rotineiramente e estar acessíveis desde o início do desenvolvimento.

A Teoria inclui dois esquemas que são diretamente relevantes para o se-esquema para prova condicional e modus ponens - e um esquema bastante relacionado que é o esquema para introdução de negação. Esses três esquemas podem ser apresentados informalmente como segue:

1. (Esquema para prova condicional)

Para derivar ou avaliar Se P então ..., primeiro suponha

$P$. Para qualquer proposição $Q$ que se segue da suposição de $P$ em conjunto com outra informação presumida, pode-se afirmar Se $P$ então $Q$.

2. (Modus Ponens)

Dado Se $P$ então $Q$ e $P$, pode-se inferir $Q$.

3. (Esquema para introdução de negação)

Quando a suposição da proposição $P$ tomada conjuntamente com outra informação suposta, conduz a uma contradição e então pode-se afirmar não $P$.

O significado de se é revelado principalmente pelo esquema para a prova condicional que afirma que, quando o conseqüente de um condicional pode ser derivado de um conjunto de suposições de premissas, tomadas juntamente com o antecedente deste condicional, como uma suposição hipotética, o condicional pode ser afirmado com base apenas na suposição das premissas. Afirmar uma oração como se é afirmar uma suposição; afirmar uma oração como então é afirmar o que segue a partir desta suposição. Quando o se é compreendido desta forma, torna-se claro porque as inferências de modus ponens são válidas: a afirmação de $S_{e} P$ então $Q$ indica que $Q$ é derivável da suposição de $P, \operatorname{logo} Q$ se segue quando a afirmação subsequente de $P$ remove a base condicional da prova. Deste modo, uma inferência modus ponens é correta porque herda a derivação do conseqüente que é feita sob o esquema para a prova condicional.

O esquema para a prova condicional, tomado junto com as rotinas de raciocínio direto, fornece um procedimento semântico para o se, isto é, procedimento para julgar quando proposições condicionais são verdadeiras 
ou falsas. Quando um condicional está para ser avaliado, as rotinas de raciocínio direto adicionam seu antecedente ao conjunto de premissas (i.e., ao conjunto de proposições adotadas na avaliação) e tratam o conseqüente do condicional como uma conclusão a ser avaliada. Deste modo, Se P então Q é julgado verdadeiro quando o conseqüente $Q$ é verdadeiro tomando-se as premissas junto com a suposição de $P$. No entanto, Se P então $Q$ é julgado falso quando o conseqüente $Q$ é falso. $\mathrm{Na}$ lógica padrão este último julgamento não seria realizado porque o antecedente pode ser falso. O esquema de lógica mental para a prova condicional conduz, desse modo, a procedimentos semânticos para o se que difere da semântica fornecida pela Tabela da Verdade para o material condicional da lógica padrão

O esquema da lógica mental para prova condicional difere da lógica padrão em um modo adicional. Esta diferença segue de uma limitação geral da lógica mental que não é encontrada na lógica padrão. Na lógica padrão, alguma coisa pode ser derivada quando as premissas são necessariamente falsas, isto é, alguma coisa se segue de uma contradição. $\mathrm{Na}$ lógica mental, contudo, nada se segue de tal situação, exceto talvez quando algum erro foi cometido, por exemplo, quando alguma proposição está sendo tratada indevidamente como uma premissa.

Uma conseqüência desta prescrição geral contra o raciocínio, a partir de premissas falsas, é uma limitação sobre quais proposições podem ser usadas em uma derivação que conduz a uma conclusão condicional a partir de uma suposição. Qualquer proposição usada sob uma suposição conduzindo a uma conclusão condicional, deve ser consistente com esta suposição (ver Braine \& O’Brien, 1998). Esta limitação tem implicações para condicionais contrafactuais, isto é, para condicionais com conseqüentes que seguem da suposição de uma proposição falsa. Alguma proposição que não seja verdadeira sob uma suposição contrafactual, não pode ser usada em um argumento que leva a uma conclusão condicional sob esta suposição. Mesmo uma proposição verdadeira é excluída se existe uma suposição contrafactual, a menos que ela seja ainda verdadeira, dada esta suposição.

O esquema final, que é relevante para a discussão de suposição, diz respeito à introdução da negação. Nem todas as suposições são realizadas pelo uso do esquema para prova condicional a fim de inferir uma conclusão condicional. Algumas vezes, uma suposição é simplesmente abandonada quando a pessoa volta a atenção para algum outro assunto. $\mathrm{O}$ esquema para introdução da negação fornece outro modo no qual uma suposição pode ser feita: quando uma suposição leva a uma contradição, esta suposição pode ser julgada falsa.
A parte básica da lógica mental - os esquemas de inferências e as rotinas de raciocínio direto (RRD) - deve ser psicologicamente válida, isto é, deve ser aplicada, essencialmente, sem erros em problemas muito simples que podem ser resolvidos e deve estar acessível no início da infância. Além disso, dada a nossa proposta de que o significado básico de se é fornecido por seus esquemas de inferências (e é revelado particularmente pelo esquema para prova condicional) em conjunto com as RRD, espera-se o uso de se logo cedo no discurso, conforme o núcleo da teoria. Isto é, que um condicional é julgado verdadeiro quando seu conseqüente sucede de seu antecedente junto com outra informação conhecida. Várias predições básicas podem então ser feitas; existe considerável evidência para apoiar estas predições, embora haja algumas lacunas.

As inferências modus ponens devem ser feitas rotineiramente por crianças e por adultos e, os dados mostram que ambos, adultos e crianças em idade escolar, assim o fazem (ver Braine \& Rumain, 1983; O’Brien, 1987; Dias \& Harris, 1988, 1990). Há também razão para se pensar que crianças pré-escolares fazem este tipo de inferências. Scholnick e Wing (1991) e Dias e Harris $(1988,1990)$ relataram inferências do tipo modus ponens sendo feitas espontaneamente nas conversações e em tarefas experimentais entre crianças de quatro anos de idade.

No estudo de Braine e O'Brien (1998) foram apresentados vários problemas a adultos com conclusões do tipo se. Os problemas se referiam a letras num quadro negro imaginário. Dada, por exemplo, uma premissa na forma Há um $P$ ou um $Q$ no quadro negro, pedia-se para julgar a conclusão condicional Se não há um $P$ no quadronegro então bá um $Q$. Os adultos universalmente respondiam que o condicional era verdadeiro. Quando se pedia para julgar Se não há um P no quadro-negro, então não bá um $Q$, eles respondiam que o condicional era falso. Estas respostas são consistentes com as predições do procedimento semântico da lógica mental, mas são inconsistentes com o que seria predito pela Tabela da Verdade do condicional material. A literatura não fornece nenhum dado sobre tais problemas com crianças e é o que pretendemos fazer nesse estudo.

\section{Experimento 1}

Este experimento objetiva investigar se crianças em idade escolar obedeceriam ao procedimento semântico da lógica mental e julgariam como verdadeiro um condicional em que seu antecedente, tomado junto com outras premissas, vincula seu conseqüente, e como falso um condicional em que seu antecedente, tomado junto com outras premissas, vinculam a negação de seu conseqüente. 


\section{Método}

\section{Participantes}

Oitenta crianças, 40 delas freqüentavam uma escola pública de classe média, predominantemente de cor branca, da cidade de Nova Iorque. Destas, 20 crianças estavam no segundo ano (variação $=6 \mathrm{a}$ e $11 \mathrm{~m}$ a $8 \mathrm{a}$ e $2 \mathrm{~m}$ ) e 20 , no quinto ano (variação $=10 \mathrm{a}$ e $1 \mathrm{~m}$ a $11 \mathrm{a}$ e $2 \mathrm{~m}$ ). As outras 40 crianças freqüentavam uma escola particular de classe média e racialmente mista em Recife, Brasil. Vinte crianças estavam no segundo ano (variação 6 a e $8 \mathrm{~m}$ a $8 \mathrm{a}$ e $6 \mathrm{~m}$ ) e 20 no quinto ano (variação $10 \mathrm{a}$ e $5 \mathrm{~m}$ a $11 \mathrm{a}$ e $7 \mathrm{~m}$ ).

\section{Tarefas e Procedimentos}

Foram construídos 16 problemas, cada um referindose aos conteúdos de uma pequena caixa de papelão. Fo dito aos participantes que cada caixa continha alguns animais e algumas frutas de brinquedo. Alguns desses itens foram mostrados a eles. Cada problema apresentava uma caixa fechada com um cartão em sua tampa. O cartão mostrava uma ou duas premissas dando informação sobre o conteúdo da caixa e uma afirmação com o se para ser avaliada a partir das premissas. Foi solicitado às crianças que julgassem se era certo ou errado declarar a conclusão partindo das premissas
Em alguns problemas as premissas, tomadas junto com a suposição do antecedente do condicional como uma premissa adicional, vinculava ao conseqüente. Estes problemas são chamados de problemas verdadeiros, porque pela Teoria da Lógica Mental eles devem ser considerados verdadeiros. Em outros problemas, as premissas, tomadas junto com a suposição do antecedente como uma premissa adicional, levam à negação do conseqüente. Esses problemas são chamados problemas falsos, pois pela Teoria da Lógica Mental devem ser considerados falsos. Os 16 problemas foram construídos de forma que formavam 8 pares de problemas. Os problemas em cada par apresentavam as mesmas formas de premissas. Em um problema de par, a conclusão tinha um conseqüente afirmativo e, no outro, um conseqüente negativo. Também, um problema de cada par era um problema verdadeiro e o outro, falso. Além do mais, metade dos problemas com conseqüentes afirmativos era verdadeira e metade dos problemas com conseqüentes negativos também. De forma semelhante, metade das sentenças antecedentes foi afirmativa e metade negativa e, em cada caso, metade dos problemas era verdadeiro e metade era falso. Em acréscimo, ocorrências de negativas nas premissas eram igualmente balanceadas através dos problemas. Este balanceamento, na distribuição de afirmativas e negativas em problemas verda-

Tabela 2. Formas dos Problemas, suas Respostas Preditas e a Proporção de Tais Respostas para os Problemas do Experimento 1

\begin{tabular}{|c|c|c|c|c|c|c|}
\hline \multirow[t]{2}{*}{ Premissas } & \multirow[t]{2}{*}{ Conclusões } & \multirow{2}{*}{$\begin{array}{c}\text { Resposta } \\
\text { Predita }\end{array}$} & \multicolumn{2}{|c|}{ Americanos } & \multicolumn{2}{|c|}{ Brasileiros } \\
\hline & & & $7 \mathrm{a}$ & $10 \mathrm{a}$ & $7 \mathrm{a}$ & $10 \mathrm{a}$ \\
\hline \multirow[t]{2}{*}{ a. $\mathrm{P}$ ou $\mathrm{Q}$} & Se não P então Q & $\mathrm{V}$ & 0,80 & 0,85 & 1,00 & 1,00 \\
\hline & Se não $\mathrm{P}$ então não Q & $\mathrm{F}$ & 0,65 & 0,80 & 1,00 & 1,00 \\
\hline \multirow[t]{2}{*}{ b. Nem P nem Q } & Se P então não Q & $\mathrm{V}$ & 0,65 & 0,85 & 0,95 & 1,00 \\
\hline & Se P então Q & $\mathrm{F}$ & 0,65 & 0,95 & 0,95 & 1,00 \\
\hline \multirow[t]{2}{*}{ c. Se P ou Q então R } & Se P então R & V & 0,75 & 0,90 & 0,95 & 0,90 \\
\hline & Se P então não R & $\mathrm{F}$ & 0,80 & 0,75 & 1,00 & 0,90 \\
\hline \multirow[t]{2}{*}{ d. Se nem P ou nem Q então não $R$} & Se não $\mathrm{P}$ então não $\mathrm{R}$ & $\mathrm{V}$ & 0,75 & 0,85 & 0,95 & 0,95 \\
\hline & Se não P então R & $\mathrm{F}$ & 0,80 & 0,75 & 0,90 & 0,95 \\
\hline \multirow[t]{2}{*}{ e. P ou Q; se Q então R } & Se não P então R & $\mathrm{V}$ & 0,80 & 0,80 & 0,45 & 0,65 \\
\hline & Se não $\mathrm{P}$ então não $\mathrm{R}$ & $\mathrm{F}$ & 0,65 & 0,95 & 0,70 & 0,75 \\
\hline \multirow{2}{*}{ f. Nem P nem Q; Se não Q então não R } & Se P então não R & $\mathrm{V}$ & 0,70 & 0,80 & 0,60 & 0,65 \\
\hline & Se P então R & $\mathrm{F}$ & 0,85 & 0,95 & 0,70 & 0,70 \\
\hline \multirow[t]{3}{*}{ g. Nem P nem Q; Se não Q então R } & Se P então R & $\mathrm{V}$ & 0,70 & 0,95 & 0,60 & 0,70 \\
\hline & Se P então não $\mathrm{R}$ & $\mathrm{F}$ & 0,80 & 0,80 & 0,60 & 0,75 \\
\hline & & & 0,65 & 0,90 & 0,65 & 0,75 \\
\hline \multirow[t]{3}{*}{ h. P ou Q; Se Q então não R } & Se não $\mathrm{P}$ então não $\mathrm{R}$ & $\mathrm{V}$ & 0,60 & 0,95 & 0,75 & \\
\hline & Se não P então R & $\mathrm{F}$ & 0,73 & 0,90 & 0,77 & 0,70 \\
\hline & & & & 0,85 & & \\
\hline \multirow[t]{2}{*}{ Totais } & & $\mathrm{V}$ & 0,73 & 0,87 & 0,83 & 0,84 \\
\hline & & $\mathrm{F}$ & 0,73 & 0,86 & 0,80 & 0,83 \\
\hline
\end{tabular}


deiros e falsos, controla viéses de respostas envolvendo negações, preferências para respostas "certas" ou "erradas" e qualquer possível estratégia ou viés nos quais respostas do tipo "certo" ou "errado" são contingentes na ocorrência ou ausência de negativas em problemas.

As formas dos oito pares de problemas e suas conclusões verdadeiras ou falsas estão apresentadas na Tabela 2. Os problemas P, Q e R são compreendidos como afirmações sobre a presença de animais ou frutas na caixa apresentada. Um problema, por exemplo, continha a premissa Há uma maçã ou uma banana na caixa e a conclusão a ser avaliada era Se não há uma maçã então não há uma banana.

Os participantes foram testados individualmente. Eles foram informados de que, primeiro lhes seria dito alguma coisa sobre o que estava na caixa e que era para eles descobrirem as respostas para uma pergunta sobre isto. Cada caixa tinha um cartão fornecendo a premissa datilografada e uma conclusão a ser avaliada. Em cada problema, o examinador lia alto a premissa e a conclusão. A seguir, a criança também deveria ler a informação em vOz alta. Havendo erro de leitura da criança, este era corrigido e o procedimento repetido (tais erros de leitura raramente ocorreram). Para cada problema, era pedido à criança para afirmar se a conclusão estava certa ou errada baseada na premissa (a Teoria da Lógica Mental prediz uma resposta "certa" para problemas verdadeiros e uma resposta "errada" para problemas falsos). Seguindo cada julgamento, era solicitado aos participantes que fornecessem uma explicação do porquê de suas respostas como forma de desencorajar a adivinhação, o "chute". Primeiro era dado ao sujeito um problema prático com as premissas: Se há um tigre na caixa, então há um limão na caixa e há um tigre na caixa; depois a conclusão: Há um tigre e um limão na caixa. Todos os sujeitos deram respostas "certas". A ordem da apresentação dos 16 problemas foi randomizada, com metade dos sujeitos em cada idade e em cada país recebendo os problemas na ordem inversa.

\section{Resultados e Discussão}

A Tabela 2 mostra as proporções das respostas preditas, isto é, "certo" nos problemas verdadeiros e "errado" em problemas falsos, para cada idade, tipo de problema e nacionalidade. Para avaliar o desempenho completo foi realizada uma ANOVA tendo como fatores nível de escolarização (2) x tipo de problema (Verdadeiros vs. Falso) x par de problemas (8) x nacionalidade (norte-americano vs. Brasileiro), com medidas repetidas para Tipo de Problema e Par de Problemas. Foi dado a cada sujeito um escore de um ponto para cada resposta predita, isto é, "certa" em um problema verdadeiro e Psicologia: Reflexão e Crítica, 2002, 15(1), pp. 27-34 “errado" em um problema falso, caso contrário era zero. Desse modo, o escore registrado em cada célula na análise era zero ou um. A interação de ordem mais alta foi usada como o termo de erro computando valores $\mathrm{F}$.

Nenhum dos efeitos principais foi estatisticamente significativo mas houve uma interação de Nível de Escolarização x Nacionalidade, $\mathrm{F}(1,76)=7,51, p<0,01 \mathrm{e}$ uma interação de Nível de Escolarização x Tipo de Problema x Nacionalidade, $\mathrm{F}(1,76)=4,96, p<0,05$.

A interação de Nível de Escolarização x Nacionalidade foi atribuída aos norte-americanos de sete anos, que comparados com os outros 3 grupos, foram menos aptos em dar as respostas preditas. Comparações entre todos os quatro grupos mostraram, entretanto, que a média de cada grupo era significativamente maior do que o acaso $(=50)$, $t(19)=3.24, p<0,01$ para os norte-americanos de sete anos, $t(19)=5.48, p<0,001$ para os norte-americanos de dez anos, $t(19)=5.09, p<0,001$ para os brasileiros de sete anos e $t(19)=5.24, p<0,001$ para os brasileiros de dez anos. As tendências gerais de respostas foram, dessa forma, completamente consistentes com as predições da Teoria da Lógica Mental.

A interação de Nível de Escolarização x Par de Problemas x Nacionalidade foi atribuída aos brasileiros de 7 anos, cujas respostas para os pares de problemas (e) e (g) foram menos prováveis de serem aquelas preditas do que eram as respostas aos pares de problemas (a) e (d). O problema verdadeiro do par (e) foi o único problema no qual, em nenhum grupo, a resposta predita pela Teoria da Lógica Mental não foi fornecida por pelo menos $60 \%$ dos participantes. A observação das justificativas das crianças revelou que elas resistiam à resposta predita verdadeira, neste problema, porque ele envolvia a colocação de um pássaro e um peixe juntos, e muitas crianças diziam que "um pássaro não pode viver com um peixe porque o peixe não pode voar e pássaros não podem viver na água".

Quando os dados para os norte-americanos e brasileiros de sete anos foram agrupados, em 15 dos 16 problemas as respostas preditas foram dadas em uma freqüência acima do acaso (para 40 sujeitos, o acaso é abaixo de $65 \%$ em um teste binomial). A única exceção foi o problema verdadeiro (e) para os brasileiros de sete anos (foi apresentado a uma amostra adicional de 20 crianças brasileiras o mesmo problema, mas com animais diferentes, para que a incompatibilidade epistêmica fosse eliminada e $80 \%$ das crianças deu a resposta predita VERDADEIRO na nova versão do problema). Quando os dados para os norte-americanos e brasileiros de dez anos foram agrupados, a resposta predita era dada em uma freqüência acima do acaso em todos os problemas. 
A ausência de algum efeito significativo para problemas verdadeiros versus falsos, indica que as crianças não respondiam baseadas nas preferências de respostas e a incidência de respostas "certo" ou "errado" não era influenciada nem pela falta nem pelo número de negações em um problema. Assim, as tendências das respostas foram consistentes com aquelas preditas pela teoria

Por serem as justificativas das respostas dos participantes às vezes incompletas e difíceis de interpretar, ela não foram tratadas estatisticamente. Contudo, elas geralmente eram consistentes com a linha de raciocínio esperada. Por exemplo, explicando uma resposta "falsa" à conclusão condicional Se não há uma maçã, então não há uma banana, da premissa: Há ou uma maçã ou uma banana, uma criança de 7 anos disse "porque ali haveria uma banana". Tais explicações eram típicas em ambas as idades e em ambas as nacionalidades.

Em suma, as crianças neste experimento foram capazes de dar as respostas preditas a estes problemas com conclusões condicionais na maioria das vezes, e suas tendências de respostas foram as mesmas do que aquelas relatadas previamente em adultos.

\section{Experimento 2}

Os resultados no Experimento 1 mostram que as crianças, em idade escolar, julgam como verdadeiros aqueles condicionais em que uma suposição, tomada junto com outra informação/premissa, leva ao conseqüente e, julgam como falsos aqueles em que uma suposição, tomada junto com outra informação/premissa, conduz à negação do conseqüente. Assim, elas respondem da mesma forma que os adultos citados em Braine, O’Brien, Noveck, Samuels, Lea, Fisch e Yang (1998), exatamente como a Teoria da Lógica Mental prediz.

Os resultados, contudo, deixam uma questão em aberto. As respostas "falsas" no Experimento 1, não eram separadas claramente das respostas "não posso dizer". Uma criança pode usar a opção de resposta "falsa" por que não foi dada nenhuma opção intermediária clara (naturalmente, teríamos gravado tais respostas se tivessem sido ditas, mas não o foram). Este fato exige investigação porque as predições da lógica mental para esses problemas "falsos" diferem do que seria esperado na lógica padrão, na qual uma resposta "não posso dizer" seria apresentada. Além do mais, na ausência de uma opção clara de resposta "não posso dizer", a opção falsa pode estar sendo usada para indicar que a conclusão não resul ta das premissas e não pra informar que a negação da conclusão se segue das premissas. Nos problemas aqui apresentados, era dado aos participantes uma opção cla- ra de resposta "não posso dizer" e algum treinamento no seu uso.

\section{Método}

Participantes: sessenta norte-americanos e 60 brasileiros. Entre os norte-americanos, haviam 20 de segunda série (variação: $6 \mathrm{a}$ e $9 \mathrm{~m}$ a $7 \mathrm{a}$ e $7 \mathrm{~m}$ ) e 20 estudantes de quinta série (variação; 9 a e $8 \mathrm{~m}$ a 11 a e $1 \mathrm{~m}$ ) e 20 estudantes universitários de Introdução à Psicologia da Universidade de Nova Iorque. Foram omitidos quatro alunos da segunda série, porque falharam em alcançar o critério na tarefa de treinamento descrito posteriormente. As crianças eram oriundas de duas escolas de raça mista de classe média, da cidade de Nova Iorque, sendo uma pública e uma particular. Entre as brasileiras, haviam 20 estudantes de segunda série (variação: $6 \mathrm{a}$ e $4 \mathrm{~m}$ a $7 \mathrm{a}$ e $11 \mathrm{~m}), 20$ de quinta série (variação: 9 a e $6 \mathrm{~m}$ a 10a e $10 \mathrm{~m}$ ) e 20 universitários da Universidade Federal de Pernambuco. Dois outros brasileiros de segunda série foram omitidos porque falharam em alcançar o critério na tarefa de treinamento. Os brasileiros de segunda e quinta série eram de duas escolas particulares, de raça mista, de classe média em Recife, Brasil.

Tarefas e Procedimentos: Foram apresentados quatro problemas e, como no Experimento 1, eles se referiam aos conteúdos de uma caixa fechada que continham frutas e animais de brinquedo. Todos os quatro problemas tinham o mesmo par de premissas: nesta caixa bá uma vaca ou um cavalo, mas não os dois. Há também uma fruta. As quatro conclusões a serem avaliadas eram: (a) Se bá uma vaca então não há um cavalo (verdadeiro); (b) Se há uma vaca então bá uma banana (não posso dizer); (c) Se há um cavalo então há uma vaca (Falso); e (d) Se há um cavalo então não bá uma laranja (Não posso dizer). Para metade dos participantes em cada grupo, estes quatro problemas foram apresentados na ordem acima mencionada, e para a outra metade, eles foram apresentados na ordem inversa.

O formato e procedimento foram os mesmos do Experimento 1, exceto por duas alterações. Uma era que as conclusões a serem avaliadas eram atribuídas a uma marionete chamada "Tonton". Os sujeitos tinham de dizer "Se Tonton está certo ou errado, ou que você não pode dizer se ele está certo ou errado porque você não sabe bastante sobre o que está na caixa". A outra alteração foi uma tarefa de treinamento que era dada em lugar de um problema prático. Haviam 12 problemas de treinamento, quatro determinados (dois verdadeiros e dois falsos) e oito indeterminados. Estes problemas também se referiam ao conteúdo (animais e frutas de brinquedo) de uma caixa fechada. Os problemas indeterminados ilus- 
Tabela 3. Proporções de Respostas "Verdadeira", "Falsa" e "Não pode dizer" para os Problemas "Verdadeiro", "Falso" e "Não pode dizer" em Cada Nível de Idade no Experimento 2

\begin{tabular}{|c|c|c|c|c|c|c|c|}
\hline \multirow[t]{2}{*}{ Idade } & \multirow[t]{2}{*}{ Tipo de problema } & \multicolumn{3}{|c|}{ Americanos } & \multicolumn{3}{|c|}{ Brasileiros } \\
\hline & & Verdadeiro & Falso & Não pode dizer & Verdadeiro & Falso & Não pode dizer \\
\hline \multirow[t]{3}{*}{7 anos } & Verdadeiro & 0,65 & 0,05 & 0,30 & 0,85 & 0,00 & 0,15 \\
\hline & Falso & 0,00 & 0,80 & 0,20 & 0,00 & 1,00 & 0,00 \\
\hline & Não pode dizer & 0,03 & 0,08 & 0,90 & 0,00 & 0,50 & 0,50 \\
\hline \multirow[t]{3}{*}{10 anos } & Verdadeiro & 0,95 & 0,00 & 0,05 & 0,90 & 0,00 & 0,10 \\
\hline & Falso & 0,00 & 1,00 & 0,00 & 0,00 & 1,00 & 0,00 \\
\hline & Não pode dizer & 0,03 & 0,18 & 0,80 & 0,00 & 0,50 & 0,50 \\
\hline \multirow[t]{3}{*}{ Adultos } & Verdadeiro & 1,00 & 0,00 & 0,00 & 1,00 & 0,00 & 0,00 \\
\hline & Falso & 0,00 & 1,00 & 0,00 & 0,00 & 1,00 & 0,00 \\
\hline & Não pode dizer & 0,05 & 0,18 & 0,78 & 0,00 & 0,44 & 0,56 \\
\hline
\end{tabular}

tram sua natureza geral. O primeiro problema apresentava a premissa Há um gato ou um cachorro e a conclusão a ser avaliada é Há um gato (não posso dizer). Nenhum dos problemas de treinamento tinha conclusões condicionais. Os sujeitos só eram aceitos no estudo se dessem quatro respostas corretas consecutivas (caso em que o treinamento era interrompido) ou se acertassem os últimos seis problemas. Quatro crianças de Nova York e duas brasileiras do segundo ano do Ensino Fundamental falharam neste critério e foram excluídas do estudo. Não foi dado qualquer retorno (feedback) aos problemas. Mais detalhes relativos a este procedimento de treinamento são fornecidos em O’Brien e colaboradores (1989, Experimento 2).

\section{Resultados e Discussão}

Proporções das respostas Verdadeiro, Falso e Não posso dizer para os problemas Verdadeiro, Falso e Indeterminado são apresentadas na Tabela 3. Nos quatro problemas, tanto as crianças norte-americanas como as brasileiras de sete anos, deram as respostas preditas em $78 \%$ das vezes, uma proporção que excedeu o que seria esperado unicamente pelo acaso $(=0,33), Z=4,28, p<0,001$. Já nos dois grupos a proporção de sujeitos oferecendo respostas preditas para todos os quatro problemas $(=0,45)$ foi maior do que seria esperado apenas pelo acaso $(=0,012)$, $Z=17,99, p<0,001$. Para as norte-americanas de dez anos e adultos, mais participantes deram respostas preditas ( $92 \%$ e $93 \%$ respectivamente), como foi o caso de brasileiros de dez anos de idade e adultos (80\% e $85 \%$ respectivamente). Os dois grupos de nacionalidade em to- das as três idades deram assim, freqüentemente, mais respostas esperadas pelo acaso.

Uma característica dos dados da Tabela 2 que não foi predita é que os brasileiros mostraram menos uso da opção de resposta Não posso dizer nos problemas Indeterminados do que os norte-americanos. Contudo, é de maior interesse aqui o fato de que nenhum grupo usou a resposta Não posso dizerer em problemas falsos, o que é consistente com nossa previsão de que os problemas "falsos" produziriam respostas Falso em vez de respostas Não pode dizer que seriam preditas na lógica padrão. Tomados juntos com os resultados do Experimento 1 , os dados revelam que crianças em idade escolar, assim como adultos, deram respostas para problemas com conclusão condicional. Este fato corresponde às previsões da lógica mental baseadas no esquema para prova condicional juntamente com a rotina do raciocínio direto.

\section{Discussão Geral}

Conforme foi descrito na introdução, a literatura anterior fornece considerável evidência apoiando as predições da parte central da Teoria da Lógica Mental para o raciocínio condicional, mas não revela se crianças fazem julgamentos que são consistentes com o procedimento semântico da lógica mental para se. Os experimentos aqui mencionados fornecem evidências a este respeito. Eles mostraram que crianças em idade escolar, assim como os adultos, fazem julgamentos que são consistentes com os procedimentos semânticos da lógica mental para se.

Assim, há razões para se pensar que existe uma lógica para condicionais que se centraliza na suposição e que 
está disponível logo cedo na linguagem e no raciocínio das crianças. Visto que há evidência empírica, com crianças e adultos, para cada uma das fases desta parte básica da lógica mental que propusemos, afirmações de que não existe uma lógica mental em crianças ou adultos para a compreensão de condicionais, em nossa opinião, são totalmente equivocadas.

\section{Referências}

Braine, M. D. S. \& Rumain, B. (1983). Logical reasoning. Em J. H. Flavell \& E. Markman (Orgs.), Handbook of cbild psychology. 3. Cognitive developmen (pp. 263-339). New York: Wiley.

Braine, M. D. S. \& O'Brien, D. P. (1998). A theory of if: A lexical entr reasoning program, and pragmatic principles. Em M.D.S. Braine \& D.P. O’Brien (Orgs.), Mental Logic (pp.199-244). Mahwah, N.J: Lawrence Erlbaum

Braine, M. D. S., O’Brien, D. P. Noveck, I. A., Samuels, M. C., Lea, R. B, Fisch, S. M. \& Yang, Y. (1998). Further evidence for the theory: Predicting intermediate and multiple conclusions in propositional logic influence problems. Em M. D. S. Braine \& D. P. O'Brien (Orgs.), Mental logic (pp. 145-198). Mahwah, N.J: Lawrence Erlbaum.

Dias, M. G. \& Harris, P. J. (1988). The effect of make-believe play on deductive reasoning. British Journal of Developmental Psychology, 6, 207-221.
de ductive reasoning. British Journal of Developmental Psychology, 6, 207-221.
Dias, M. G., \& Harris, P. J. (1990). The influence of the imagination on Dias, M. G., \& Harris, P. J. (1990). The influence of the imagination on
reasoning in young children. British Journal of Developmental Psycholog, 8, 305-318.

Ennis, R. H. (1971). Conditional logic and primary school children: A developmental study. Interchange, 2, 126-132

Ennis, R. H. (1975). Children's ability to handle Piaget's propositional logic. Review of Educational Research, 45, 1-41.

Evans, J. St. B. T. (1982). The psychology of deductive reasoning. London: Routledge \& Kegan Paul.

Evans, J. St. B. T., Newstead, S. E. \& Byrne, R. M. J. (1993). Human reasoning: The psychology of deduction. Hove, UK: Erlbaum.

Knifong, J. D. (1974). Logical abilities of young children-two styles of apKnifong, J. D. (1974). Logical abilities of young children-two styles of approach. Child Development, 45, 78-8

uhn, D. (1977). Conditional reasoning in children. Developmental Psycholog, 13, 342-353.
Leslie, A. M. (1987). Pretense and representation: The origins of "theory of mind." Psychological Reviem, 94, 412-426.

Markovits, H. (1984). Awareness of the 'possible' as a mediator of formal thinking in conditional reasoning problems. British Journal of Psychology, 75, 367-376.

Markovits, H. (1985). Incorrect conditional reasoning among adults: Competence or performance?_British Journal of Psychology, 76, 241-247.

Matalon, B. (1962). Etude genetique de l'implication [A genetic study of implication]. Etudes d'epistemologie genetique. 16. Implication, formalisation et logique naturelle, 69-93.

Moshman, D. (1979). Development of formal hypothesis-testing ability. Developmental Psychology, 15, 104-112.

O’Brien, D. P. (1987). The development of conditional reasoning: An iffy Brien, D. P. (1987). The development of conditional reasoning: An iffy
proposition. Em H. Reese (Org.), Advances in cbild bebavior and development (pp. 66-91). New York: Academic Press.

O’Brien, D. P., Braine, M. D. S., Connell, J. W., Noveck, I. A, Fisch, S. M. \& Fun, E. (1989). Reasoning about conditional sentences: Development of understanding of cues to quantification. Journal of Experimental Child Psychology, 48, 90-113.

Overton, W. F. (1990). Competence and procedures: Constraints on the development of logical reasoning. Em W. F. Overton (Org.), Reasoning, necessity, and logic: Developmental perspectives (pp. 1-32). Hillsdale, NJ: Lawrence Erlbaum Associates.

Paris, S. (1973). Comprehension of language connectives and propositional logic relation ships. Journal of Exprimg connectives and propostional Scholnick, E. S. \& Wing, C. S. (1991). Speaking deductively: Preschoolers' use of if in conversations and in conditional. Developmental Psychology,
und use of if in
$27,249-258$.

Staudenmayer, H. \& Bourne, L. (1977). Learning to interpret conditional sentences: A developmental study. Developmental Psychology, 13, 616-623. Taplin, J. E., Staudenmayer, H. \& Taddonio, J. L. (1974). Developmental changes in conditional reasoning: Linguistic of logical? Journal of Experimental Child Psycbology, 17, 360-373.

Ward, S. L. \& Overton, W. F. (1990). Semantic familiarity, relevance, and the development of deductive reasoning. Developmental Psychology, 26, 488493.

Recebido: 17/04/2001 Revisade: 06/09/2001 Aceito: 25/09/2001

Sobre os autores

Maria da Graça Bompastor Borges Dias é PhD em Psicologia do Desenvolvimento pela University of Oxford, Inglaterra, Professor Adjunto do Departamento de Psicologia da Universidade Federal de Pernambuco.

Antonio Roazzi é PhD em Psicologia do Desenvolvimento pela University of Oxford, Inglaterra Profesor Adjuntodo Departamento de Psicologia da Universidade Federal de Pernambuco.

David Paul O'Brien é PhD em Filosofia pela University of Philadelphia, Professor de Psicologia Cognitiva da The City University of New York (CUNY), N.Y., USA.

Martin Braine (in memoriam) foi Professor de Psicologia Cognitiva da New York University (NYU), N.Y., USA. 